Copyright by the Ecological Society of America

LEAF PHENOLOGY OF WOODY SPECIES IN A NORTH AUSTRALIAN TROPICAL SAVANNA

R. J. Williams, B. A. Myers, W. J. Muller, G. A. Duff, and D. Eamus

Ecology 1997 78:8, 2542-2558 


\title{
LEAF PHENOLOGY OF WOODY SPECIES IN A NORTH AUSTRALIAN TROPICAL SAVANNA
}

\author{
R. J. Williams, ${ }^{1,4}$ B. A. Myers, ${ }^{2}$ W. J. Muller, ${ }^{3}$ G. A. Duff, ${ }^{2,4}$ And D. Eamus ${ }^{2,4}$ \\ ${ }^{1}$ CSIRO Division of Wildlife and Ecology, Tropical Ecosystems Research Centre, PMB 44 Winnellie, \\ Northern Territory, Australia \\ ${ }^{2}$ School of Biological Sciences, Northern Territory University, 0909, Northern Territory, Australia \\ ${ }^{3}$ CSIRO INRE Biometrics Unit, G.P.O. Box 1666 Canberra, Australian Capital Territory 2601, Australia \\ ${ }^{4}$ Cooperative Research Centre for the Sustainable Development of Tropical Savannas, \\ Northern Territory University, 0909, Northern Territory, Australia
}

\begin{abstract}
Leaf phenology was monitored for 49 woody species (trees and tall shrubs) each month over a 2.5 -year period in a humid, wet-dry tropical eucalypt savanna at Solar Village, near Darwin, Australia. In the 10 most common species, which spanned the range of phenological types, phenology was monitored every two weeks. To investigate the relationships between leaf phenology and plant water status, pre-dawn leaf water potential was monitored in eight common species every 4-6 weeks. Four main phenological types were described: (1) evergreen species, which retained full canopy throughout the year; (2) brevi- or partly deciduous species, in which the amount of canopy fell significantly, but briefly, during at least one dry season during the study period, but to levels not below $50 \%$ of full canopy; (3) semideciduous species in which canopy fell to below $50 \%$ of full canopy in each of the dry seasons; and (4) fully deciduous species, which lost all leaves during the early-mid dry season, and remained leafless for at least one month. Of these 49 species, $24 \%$ were evergreen, $20 \%$ were brevideciduous, $29 \%$ were semideciduous, and $27 \%$ were fully deciduous. Leaf fall occurred 1-2 months earlier in the dry season for the fully deciduous species than for the semideciduous species. Leaf fall in all species was coincident with the attainment of seasonal minima in leaf water potential, which were, on average, about -1.5 to $-2.0 \mathrm{MPa}$ in the evergreen and semideciduous species, compared with about -0.5 to $-1.0 \mathrm{MPa}$ in the fully deciduous species. Leaf flushing occurred throughout the dry season in the two evergreen species, with a major peak in the late dry season. In five semideciduous species and one of the fully deciduous species, leaf flushing commenced in the late dry season prior to the occurrence of any rain. In two fully deciduous species, leaf flushing occurred only after the first storms of the early wet season. There was variation in the timing of flushing, both between species within years and between years for some species. However, all species commenced leaf flushing after water potentials rose, following the attainment of seasonal minima in pre-dawn leaf water potential. Soil moisture at $1 \mathrm{~m}$ did not fall below permanent wilting point during the dry season; hence, reserves of soil water at the end of the dry season were sufficient to support the whole-plant rehydration that preceded leaf flushing in the absence of rain. These results are consistent with hypotheses, developed in the neotropics, that leaf phenology in trees from the wet-dry tropics is largely controlled by endogenous mechanisms.
\end{abstract}

Key words: Australia; deciduous trees and shrubs; Eucalyptus; leaf flush; phenology; savanna; synchrony; tropical savanna; water potential.

\section{INTRODUCTION}

Tropical savannas are a substantial biome across the world. Savannas consist of a discontinuous stratum of trees over a more or less continuous layer of grasses (Brouliere 1983, Huntley and Walker 1985). Despite this apparent structural simplicity, there is high diversity of both species and life-forms represented within savannas, within both the herbaceous and woody strata (Bowman et al. 1993, Egan and Williams 1995, Wilson et al. 1996). The climate of tropical savanna regions

Manuscript received 5 May 1996; revised 8 May 1996; accepted 26 November 1996; final version received 7 February 1997 is distinctly seasonal, with a summer wet season followed by a dry season, during which little or no rain falls (Huntley and Walker 1985, Tothill and Mott 1985). In tropical savannas, the temporal patterns in growth and reproduction are linked to the rhythms of the various seasons. Numerous woody species, both dominant and subdominant, are deciduous, with leaf fall occurring during the dry season. Major flushing, flowering, and fruiting events may occur at various times during both the wet and the dry season (Fensham and Bowman 1992). There may be considerable variation between years, species, and life-forms in the timing of major phenological events (Sarmiento and Monasterio 1983, van Schaik et al. 1993). 
In Australia, tropical savannas are the predominant vegetation type in the northern region of the country, occupying $\sim 20 \%$ of the continent. Rainfall varies from $<500 \mathrm{~mm} / \mathrm{yr}$ to $>1800 \mathrm{~mm} / \mathrm{yr}$, and $>90 \%$ falls in the wet season between November and April (Bureau of Meteorology 1988). In Australian savannas, the occurrence of the wet season is predictable, in that the convectional storms and the monsoon always deliver rain each year. However, there is considerable interannual variability in the duration and the timing of both the onset and end of the wet season (Taylor and Tulloch 1985). Although there are distinct wet and dry periods, six seasons within the year, each approximately two months long, may be recognized (Braithwaite and Estbergs 1988): (1) the early storm period (October-November), often referred to as the "buildup" and characterized by increases in atmospheric humidity and patchy convective storms; (2) the early monsoon (December-January), characterized by onset of the monsoon; (3) the late monsoon (February-March), when most rain falls; (4) the late storms (April-May), representing the transition between wet season and dry season; (5) the cool dry (June-July); and (6) the hot dry (August-September), when temperatures are high and both soil and atmospheric moisture levels are lowest.

Australian savannas are, in general, dominated by Eucalyptus species in the upperstory, with a variety of annual and perennial $\mathrm{C}_{4}$ grasses dominating the understory. Broadleaf, pantropical trees and shrubs may occur in the upper-midstories; many of these species are deciduous (Bowman et al. 1988, Wilson et al. 1996). In the Northern Territory, the structure of the savannas varies from open forest (sensu Specht 1981) in the wetter coastal and subcoastal regions of the north, to woodlands and low open woodlands of the more arid interior. Various phenological types, from evergreen to deciduous, occur within the woody component of the savannas (Wilson et al. 1990, 1996).

There have been fewer studies of phenological patterns of trees and shrubs in the savannas of the Australian tropics (Bowman et al. 1991, Dunlop and Webb 1991, Burrows and Burrows 1992, Wilson et al. 1996), compared with numerous studies in other savanna areas of the world (e.g., Africa: Menaut and Cesar 1979, Chidumayo 1990; South America: Monasterio and Sarmiento 1976, Medina 1982, Sarmiento and Monasterio 1983, Medina and Silva 1990; India: Yadava 1990). In conjunction with phenological studies in closed-canopy rain forests in the seasonal tropics, these studies have identified major issues with respect to ecosystem form and function: the extent of deciduousness, the nature of phenological types or guilds, the timing and degree of synchrony of the major phenophases, and the proximate and ultimate causes of phenological events (Reich and Borchert 1982, 1984, van Schaik et al. 1993, Borchert 1994a, b, $c$, Reich 1995).

In Australian savannas, there has been no long-term, quantitative assessment of the variation in the patterning of leaf fall and leaf flush between species and between years. Moreover, the relationships between plant water status and leaf fall and leaf flush are also unknown. The aim of this paper is to quantify the interseasonal and interannual patterns of leaf phenology for 49 woody species in a stand of eucalypt savanna, near Darwin, and to relate these patterns to variation in soil moisture and whole-plant water status. We ask the following key questions. What is the seasonal pattern of foliage abundance? What is the degree of variation in deciduousness within the woody species? When are the peak periods of leaf fall and leaf growth? Is the timing of leaf fall and leaf flush synchronous between species, and between individuals within species? What interannual variation exists in these patterns? Are the major leaf phenophases associated with changes in the internal water balance of the plant (the degree of hydration), as proposed by Reich and Borchert $(1982,1984)$ ?

\section{Study Site}

The study was carried out at Solar Village $\left(\sim 12^{\circ} 40^{\prime}\right.$ $\left.\mathrm{S}, 131^{\circ} 10^{\prime} \mathrm{E}\right), 35 \mathrm{~km}$ southeast of Darwin, in the wetter end of the Australian savanna biome, from September 1992 to February 1995. The site is described in detail by Fensham (1990). Annual rainfall is $\sim 1600 \mathrm{~mm}$. Temperatures are high year-round: average January (wet season) maximum and minimum temperatures are $31.8^{\circ} \mathrm{C}$ and $24.8^{\circ} \mathrm{C}$, respectively; the corresponding averages for July (dry season) are $30.5^{\circ} \mathrm{C}$ and $20.0^{\circ} \mathrm{C}$. The vegetation is open forest (sensu Specht 1981) dominated by Eucalyptus miniata and E. tetrodonta, with a variety of woody species such as Erythrophleum chlorostachys, Xanthostemon paradoxus, and Terminalia ferdinandiana as canopy subdominants, over a sparse understory of perennial and annual grasses such as Sorghum, Chrysopogon, and Ericahne spp., and small shrubs. The soil is a sandy loam overlying lateritic hardpan layers $0.5-1.5 \mathrm{~m}$ beneath the surface. This vegetation-soil alliance is typical for the higher rainfall areas in the Top End of the Northern Territory (Wilson et al. 1990, 1996, Williams et al. 1996). The site has not been burned since 1978, a fire-free period that is unusual for Australian savannas (Braithwaite and Estbergs 1985). The climate of the Darwin region is described in detail by McDonald and McAlpine (1991).

\section{Methods}

\section{Regional and site climate and microclimate}

Monthly rainfall data for the study period (September 1992-February 1995) were compiled from records collected at two Australian Bureau of Meteorology rainfall stations: Collard Road, $\sim 5 \mathrm{~km}$ from the study site, and Darwin Airport, $\sim 35 \mathrm{~km}$ from the site. Average monthly values for relative humidity (at 1500) for the period of the study, and average monthly longterm mean global daily irradiance were calculated from 
the Darwin Airport climatic data set (Australian Bureau of Meteorology). Volumetric soil moisture content was measured at eight locations along a $150-\mathrm{m}$ transect at the study site, using a portable TDR system (TRASE Instruments, Soil Moisture Equipment Corporation, Goleta, California USA). Depths of $0-50 \mathrm{~cm}$ and $0-$ $100 \mathrm{~cm}$ were sampled every 2-4 weeks from April 1993 to January 1995.

\section{Species selection}

Within an area of $\sim 2$ ha, reproductively mature individuals of 49 woody species (trees and tall shrubs) were selected and tagged. Depending on abundance, 2-10 individuals were tagged for each species; there were 2-3 replicates for the less common species and 10 replicates for the 10 most common species. Individuals of the 10 most common species were located within a $160 \times 50 \mathrm{~m}$ belt transect. These 10 species were Eucalyptus miniata, E. tetrodonta, E. porrecta, E. clavigera, Xanthostemon paradoxus, (Myrtaceae), Erythrophleum chlorostachys (Caesalpiniaceae), Terminalia ferdinandiana (Combretaceae), Cochlospermum fraseri (Bixaceae), Planchonia careya (Lecythidiaceae), and Buchanania obovata (Anacardiaceae); nomenclature follows Dunlop et al. (1990). For the two dominant trees, Eucalyptus miniata and E. tetrodonta, 10 reproductively immature, sapling stage individuals (height 4-6 m; diameter at breast height $<10 \mathrm{~cm}$ ) were surveyed, in addition to the 10 adult individuals. These 10 species constitute $>95 \%$ of the tree basal area at the site, as they do for most savannas in the Darwin region (Wilson et al. 1990).

\section{Assessment of phenological state}

Over the period September 1992-February 1995, observations of the vegetative state of each individual were made at the beginning of each month for the less common species and twice per month (beginning and middle) for the 10 common species. Reproductive phenology was also recorded; the seasonal variation in these patterns will not be reported in detail in this paper.

For each individual tree, the phenological state of the foliage was described in terms of the following four categorical variables, which incorporated estimates of canopy abundance and the amount and type of foliage.

1) Canopy fullness: the amount of canopy as a proportion of the potentially complete cover, as defined by the extent of the outer, live branches in the canopy. The scales of cover were 0 , absent; $1,<2 \% ; 2,2-25 \%$; $3,26-50 \%$; 4, 51-75\%; $5,>75 \%$ cover.

2) New foliage: the percentage, by estimated area, of the canopy that consisted of new, young foliage. Such foliage in all species was easily distinguishable from older, mature foliage on the basis of leaf color and/or size. Categories were 0-4 (as for the canopy fullness variable); 5, 75-99\% cover; and 6, 100\% new foliage.

3) Leaf buds: the percentage, by estimated number, of new foliage that consisted of leaf buds (juvenile, unexpanded leaves $<0.5 \times$ the length of a fully expanded adult leaf). Categories were $0-6$, as in variable (2).

4) Expanded leaves: the percentage, by number, of new foliage that consisted of more or less expanded leaves $(>0.5 \times$ adult leaf length). Categories were $0-$ 6 , as in variable (2).

\section{Litter fall}

To assess the seasonal patterns of leaf fall, litter traps were placed under seven trees of each of eight of the 10 major species (Buchanania obovata and Eucalyptus porrecta were not sampled). These traps were made of nylon shade cloth that hung from a metal ring $(0.6 \mathrm{~m}$ in diameter), held at $\sim 1 \mathrm{~m}$ from the ground. Two traps were placed under each of the larger trees and one under each of the smaller trees. The contents of the traps were collected each month from September 1992 to December 1994. These samples were sorted into the leaves of the target species, leaves of other species, and miscellaneous fragments (bark, fruit, etc.). The sorted samples were oven-dried to constant mass at $60^{\circ} \mathrm{C}$ and weighed. Leaf fall was expressed in grams per square meter per tree.

\section{Data analysis}

Community-wide patterns. - Categorical abundance measures of each phenological variable for each individual tree were converted to their midrange (median) percentage values. For each of the 30 sample months, the median value of each phenological variable was calculated for each of the 49 species. From the medians for canopy fullness and new foliage, an index of growth was calculated for each species at each month:

$$
\begin{aligned}
\text { growth index }= & {[\text { median canopy fullness }} \\
& \times \text { median new foliage }] / 100
\end{aligned}
$$

where median canopy fullness and median new foliage are both expressed as percentages. This index was constrained between 0 and 87.5 by the definition of its component variables.

Overall community-wide trends (pooled species) were obtained for canopy fullness and the growth index by calculating means over the 49 species for each month. Leaf growth was further analyzed by calculating, at each month, the percentage of the 49 species with (a) leaf buds, and (b) expanded leaves, present; i.e., category 1 or greater in phenological variables (3) and (4), respectively.

The 49 species were categorized into leaf phenological types (evergreen through deciduous) on the basis of the degree of canopy fullness exhibited by each species over the study period. For 1993 and 1994, when monthly data were available for the whole of the year, the absolute minimum canopy fullness for each species during the year was calculated. 
Differences between phenological types were assessed for canopy traits such as minimum canopy cover and the duration of low canopy cover. These were not tested by formal statistical means, because the canopy characteristics were used to define the types. We did, however, test for formal statistical differences between types in the growth characteristics, which were not used in the classification. Difference between types in the growth index at peak flushing time, and the timing of growth initiation, were tested using a two-factor ANOVA with type differences tested against species within types, and year differences and the type $\times$ year interaction tested against species within types $\times$ year. Homogeneity of variance was assessed by plots of standardized residuals vs. fitted values; in all cases the assumption of homogeneity was satisfied without needing to transform the data. All analyses were performed using GENSTAT 5 (Genstat 5 Committee 1994).

Ten common species.-For the 10 common species; for which there were 10 replicate individuals, more detailed statistical analyses were undertaken. For these analyses, adult and sapling stage individuals of the two dominant eucalypts (E. miniata and E. tetrodonta) were treated as separate species. The mean canopy fullness for each of the 60 bimonthly samples was calculated for each species. Bimonthly samples were assigned numerical values, such that $1=1$ January, $1.5=15$ January, . . , $12=1$ December, $12.5=15$ December. The timing of substantial, consistent reductions in canopy fullness was assessed for each species by calculating the mean sample time over all trees (using this numerical scale) at which canopy fullness fell below $75 \%$ and remained so for two or more consecutive sample periods. The timing of the initiation of growth was similarly determined by calculating the mean sample time when flushing commenced; bimonthly samples for each individual tree were assigned numerical values as before. The mean difference in time between the nadir of canopy abundance and the peak of the growth index was also calculated for each species in each year. (For some species, this was not possible in 1992, because the study commenced after their period of minimum canopy abundance).

Pre-dawn leaf or stem water potential was monitored over the study period in eight of the 10 common species (Buchanania obovata and Eucalyptus porrecta were not studied). Measurements were taken with a Scholander-type pressure chamber, every 4-6 weeks during the dry season and every 2-4 months during the wet season. Standard techniques for the measurement of pre-dawn water potential were employed. Two leaves from each of 5-7 individuals per species were sampled at any one time; stem water potential was determined for deciduous species when they were leafless during the dry season. Details of the methods and data analyses are given in Duff et al. (1997) and Myers et al. (1997).

Differences between species and between years in the major phenological events (timing of canopy loss, time of initial flushing, and difference in time between canopy minimum and growth index maximum) were tested by two-factor ANOVAs applied to their derived measures as previously determined. In these analyses, species differences were tested against replicate trees within species, and year differences and the species $X$ year interaction were tested against the residual variation. As before, the assumption of homogeneity of variance was satisfied without needing to transform the data, and the analyses were performed using GENSTAT 5.

\section{RESUlts}

\section{Regional and site climate and microclimate}

Annual rainfall during each of the two complete wet seasons of the study period (1992-1993 and 19931994) was $\sim 1650 \mathrm{~mm}$ (Fig. 1a), which was close to the long-term average for this location. The first significant rains $(>25 \mathrm{~mm})$ occurred in September in 1992; in both 1993 and 1994, such rains did not occur until October. No rain fell during the June-August period in each year, as is typical for the region (McDonald and McAlpine 1991). Seasonal variation in the pattern of relative humidity ( $\mathrm{RH}$, at 1500) over the study period (from Darwin Airport) is given in Fig. 1b. Afternoon RH was highest during the January-March period, after which there was a rapid decline to seasonal minima in the June-July period. RH increased during the JulySeptember period in each year, 1-2 months prior to the occurrence of any rains. Volumetric soil moisture content at $0-50 \mathrm{~cm}$ and $0-100 \mathrm{~cm}$ was maximal during February-March in each year (at $\sim 20-25 \%$ of volume; Fig. 1c). Soil moisture declined rapidly with the onset of the dry season in April-May. Throughout the dry season, soil moisture varied between $5 \%$ and $8 \%$ at $0-$ $50 \mathrm{~cm}$, but remained $>10 \%$ (the permanent wilting point for a sandy loam soil) at $0-100 \mathrm{~cm}$ throughout the year. Relative humidity declined steeply in AprilMay, in both 1993 and 1994, and was lowest in July. Long-term daily global irradiance averaged $\sim 20 \mathrm{MJ} / \mathrm{m}^{2}$ (Fig. 1d), with a minimum in June (early dry season) and a maximum in October.

\section{Community-wide phenological patterns}

The monthly pattern of average canopy fullness (pooled species) for the 30-month period, September 1992 to February 1995, is shown in Fig. 2. Canopy fullness was greatest in the wet-season months (December-March) and began to decline in April with the onset of the dry season. Minimum canopy levels occurred late in the dry season (September). Reestablishment of canopy commenced late in the dry season (September-October) each year, and was more or less complete by December.

The monthly variation in the growth index (pooled species) for the period September 1992 to February 1995 is shown synoptically with the seasonal canopy 

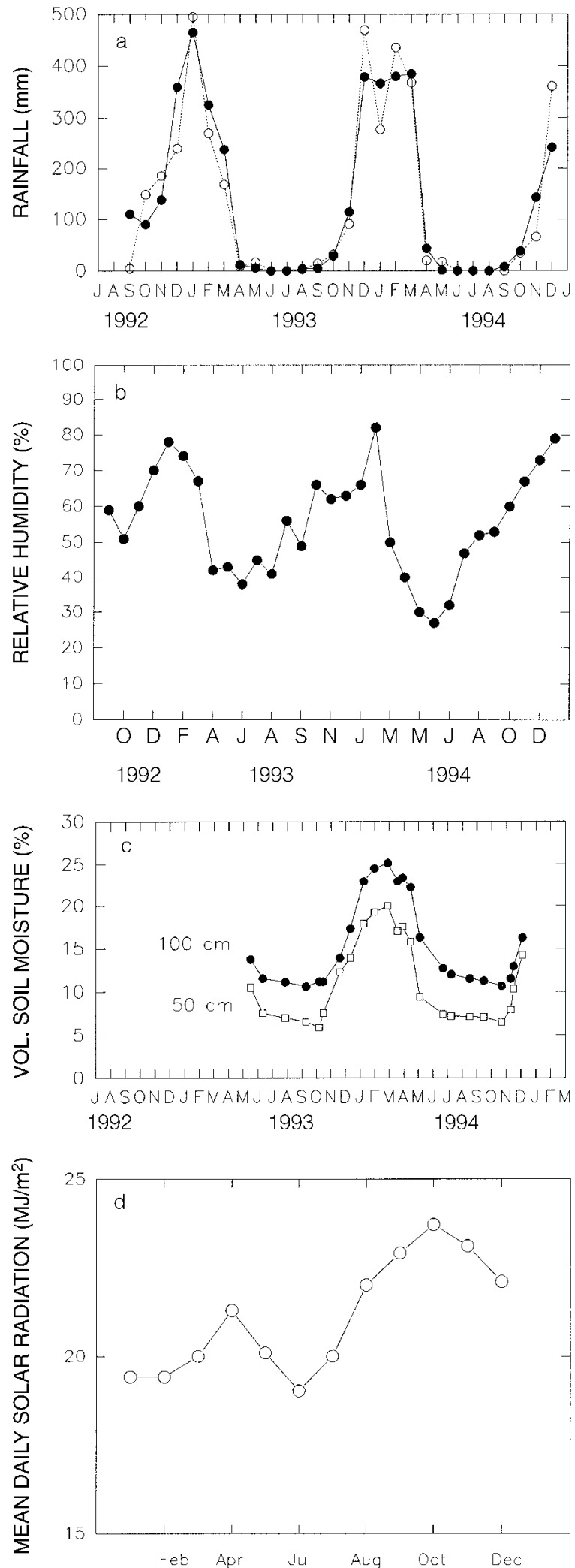

FIG. 1. Local and regional climatic data for Solar Village, Australia. (a) Monthly rainfall totals for the period September 1992 to February 1995 at the Collard Road Bureau of Me- patterns in Fig. 2. Growth occurred in all months in all years, but the seasonal pattern was very pronounced. The growth index was maximal during the late dry season/early wet season transitional period (September-November). The growth index (Fig. 2) and the proportion of species growing (Fig. 3) were both substantially greater at these times than at any other, with 75$95 \%$ of species producing new leaves. Growth was low at the end of the wet season (April-May), as measured by both the growth index and the number of species growing. Growth did not cease during the dry season (April-September), when 10-40\% of species produced new leaves (Fig. 3). Flowering was also concentrated in the mid-late dry season and buildup periods (Table 1).

Four major phenological leaf types were recognized within the 49 species surveyed (Figs. 4-7, Tables 1 and 2 ), based on the seasonal pattern of canopy abundance. Type I species were evergreen. Individual trees of such species maintained a high level of canopy $(>75 \%$ cover) throughout the year in each of the sample years (Fig. 4.) Such species accounted for $24 \%$ of the woody species surveyed (Table 1). Type II species were part deciduous, or brevideciduous (sensu Monasterio and Sarmiento 1976), with seasonal declines in the abundance of the canopy in at least one of the dry seasons during the study period, but with the average canopy fullness remaining at moderate levels $(>50 \%$ cover) throughout the year (Fig. 5; Table 1). This group accounted for $20 \%$ of the species surveyed. Type III species were semideciduous, with regular, consistent seasonal reductions in canopy fullness in the dry season to relatively low average minimum levels (15-50\% cover; Fig. 6 and Table 1). The behavior of individuals within species within this latter group varied substantially. Some individuals had definite periods of leaflessness; others maintained relatively high levels of canopy fullness, with canopies consisting of both old and new foliage. Such species accounted for $29 \%$ of those surveyed. Type IV species were fully deciduous. In this group of species every individual of each species lost all its leaves for a period of at least one month during each dry season (Fig. 7; Table 1); $27 \%$ of the species were fully deciduous.

The differences between the four phenological types in the mean minimum levels of canopy fullness, the mean duration of canopy at levels $<50 \%$, and the mean duration of leaflessness are summarized in Table 2. In

$\leftarrow$

teorology rainfall recording station, $5 \mathrm{~km}$ from the study site (O), and Darwin Airport, $35 \mathrm{~km}$ from the site $(\bigcirc)$. (b) Average daily relative humidity (at 1500 ) for each month of the study (Darwin Airport data). (c) Average volumetric soil moisture content $(\%)$ for the study period: $\bigcirc, 0-50 \mathrm{~cm} ; \bigcirc$, $0-100 \mathrm{~cm}$. For each mean, $n=8$. (d) Long-term average monthly irradiance for Darwin Airport (each month represents the mean of 20 years of records). 


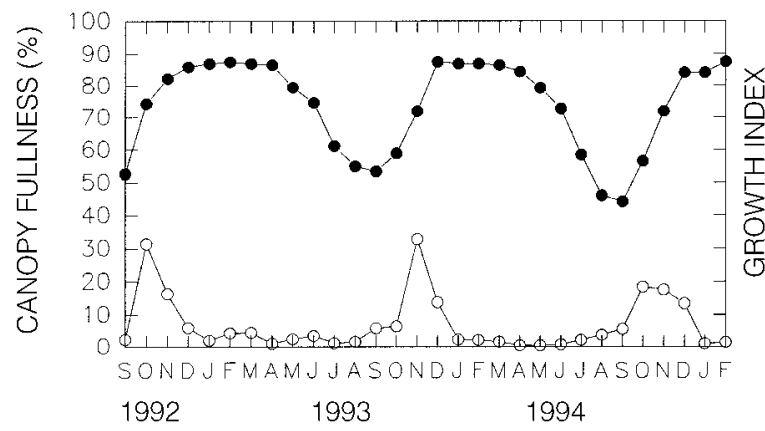

FIG. 2. Mean monthly values of the canopy fullness (O) and growth index $(\bigcirc)$, pooling 49 species, from September 1992 to February 1995.

addition to these differences between types with respect to canopy abundance, the four phenological types also exhibited significant differences in patterns of growth (Figs. 4-7, Table 2). For all types, the average peak period of growth was the transition time between the late dry and early wet seasons (September-November). However, the commencement of leaf flush was significantly earlier (by 4-6 wk) in the evergreen and brevideciduous than in the semideciduous and fully deciduous types. The four types also differed significantly in the intensity of the growth peaks, as defined by the average maximum growth indices at times of peak flush: 23.2 for evergreen species, 24.2 for brevideciduous species, 41.6 for semideciduous, and 51.0 for fully deciduous species. These differences were tested by one-way ANOVA (pooled times) for the growth parameters: Maximum Growth index $\left(F_{3,46}=18.4\right.$; SED [standard error of differences between means] $=7.1$; $P<0.001)$; and Flush Time $\left(F_{3,46}=6.3 ; \mathrm{SED}=0.7\right.$; $P<0.001)$.

\section{Patterns in the 10 common species}

The patterns displayed in the 10 common species were representative of the patterns of the four phenological types. The evergreen species were Eucalyptus miniata and E. tetrodonta; the brevideciduous species was Eucalyptus porrecta; the semideciduous species were E. clavigera, Erythrophleum chlorostachys, Xanthostemon paradoxus, and Buchanania obovata; the fully deciduous species were Terminalia ferdinandiana, Cochlospermum fraseri, and Planchonia careya.

Leaf fall.-Leaf fall occurred throughout the study period, but the seasonal patterns were very pronounced (Fig. 8). Peak leaf fall occurred in the early-mid dry season (June and July, even in evergreen species; Fig. $8 \mathrm{a})$, with secondary peaks late in the dry season ( $\mathrm{Au}$ gust-September). In 1993, leaf fall peaked in June in all types; in 1994 peak leaf fall was in May in the deciduous species (Fig. 8c), compared with August in the evergreen species and semideciduous species (Figs. $8 \mathrm{a}, \mathrm{b})$.

Variation in canopy fullness. - The seasonal patterns of canopy fullness, growth index, and leaf/stem water potential for the the dominant species are displayed synoptically in Fig. 9. Summary parameters concerning the timing of events are given in Tables 3-6. All species exhibited considerable interannual, interspecific, and interindividual variation in the timing and extent of the main phenological events and in the patterns of leaf water potential.

The evergreen species, Eucalyptus miniata and E. tetrodonta, maintained average canopy fullness levels of $\geq 75 \%$ for almost all of the study period (Fig. 9a, b), with only minor reductions in canopy during the latter part of each dry season. The juvenile, sapling stages of these two species (Fig. 9c, d) experienced more pronounced canopy reductions than their adult counterparts, with significant reductions in canopy to levels $<75 \%$ during each of the dry seasons. The semideciduous and fully deciduous species began to lose canopy at various times during the dry season. In the semideciduous species, average minimum canopy values were $20-55 \%$ (Fig. 9e-1). For species within this group, there was considerable interindividual variation in the pattern of canopy fullness. Although average canopy fullness did not reach zero at any time, some individual trees of all species in this group did have periods of leaflessness during at least one dry season. The fully deciduous species commenced canopy reduction in April-May, were leafless by May-June, and remained leafless for $1-4$ months (Fig. 9j-1).

There was considerable interspecific variation in timing of the commencement of consistent canopy reduction. This index represents that time when canopy fullness first dropped to less than maximal $(87.5 \%)$ and declined further in the following two sampling periods, for the 1993 and 1994 dry seasons (Table 3). Canopy reduction commenced earliest (May and June) in the three fully deciduous species (Cochlospermum, Terminalia, and Planchonia). This was significantly earlier than most of the semideciduous and evergreen species in each year $\left(F_{11,193}=62.9 ; P<0.001\right)$. The two dom-

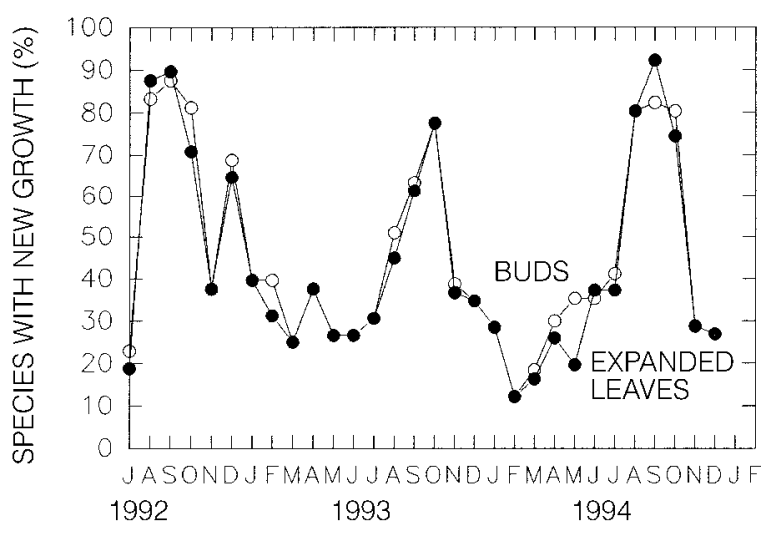

FIG. 3. The percentage of species $(n=49)$ with leaf buds (O) and expanded leaves (O) from September 1992 to February 1995 . 
TABLE 1. Summary of abundance and phenological data for evergreen, brevideciduous, semideciduous, and fully deciduous trees at Solar Village, northern Australia.

\begin{tabular}{|c|c|c|c|c|}
\hline Species & $\mathrm{BA} \dagger$ & MinCan & Growth§ & Flowering $\|$ \\
\hline \multicolumn{5}{|l|}{ A) Evergreen species } \\
\hline Eucalyptus miniata & 4.4 & Sep-Oct & Jun-Dec & May-Jul \\
\hline Eucalyptus tetrodonta & 4.0 & Sep-Nov & Jun-Dec & Jun-Sep \\
\hline Acacia auriculiformis & 1.4 & Sep-Nov & Jun-Sep & May-Jul \\
\hline Acacia mimula & 0.1 & Sep-Nov & Jun-Oct & May-Jun \\
\hline Denhamia obscura & 0.01 & Sep-Nov & Jun-Feb & Dec-Jan \\
\hline Acacia dimidiata & 0.01 & Sep-Nov & Jun-Nov & Jun-Jul \\
\hline Acacia oncinocarpa & 0.01 & Sep-Nov & Jul-Oct & May-Jun \\
\hline Exocarpus latifolius & 0.01 & Sep-Nov & Oct & Dec-Jan \\
\hline Livistona humilis & 0.01 & Sep-Nov & Jul-Nov & Jan-Feb \\
\hline Maranthes corymbosa & 0.01 & Sep-Nov & Jul-Oct & $\cdots$ \\
\hline Opilia amentacea & 0.01 & Sep-Nov & Jul-Nov & Aug-Dec \\
\hline Pandanus spiralis & 0.01 & Sep-Nov & Dec-Feb & $\cdots$ \\
\hline \multicolumn{5}{|l|}{ B) Brevideciduous species } \\
\hline Eucalyptus porrecta & 0.3 & Jul-Oct & Sep-Nov & Oct-Feb \\
\hline Acacia aulacocarpa & 0.1 & Jul-Aug & Sep-Nov & May-Aug \\
\hline Persoonia falcata & 0.04 & Jul-Aug & Jul-Nov & Jul-Nov \\
\hline Calytrix exstipulata & 0.01 & Aug-Nov & Oct-Dec & Jun-Aug \\
\hline Acacia holosericea & 0.01 & Sep-Nov & Oct-Dec & May-Aug \\
\hline Alstonia actinophylla & 0.01 & Jul-Aug & Oct-Dec & Sep-Nov \\
\hline Dodonaea oxyptera & 0.01 & Aug & Sep-Dec & $\cdots$ \\
\hline Eucalyptus bleeseri & 0.01 & Aug-Sep & Oct-Nov & Mar-Aug \\
\hline Grevillea pteridifolia & 0.01 & Aug-Oct & Nov-Feb & May-Jun \\
\hline Pittosporum melanospermum & 0.01 & Aug-Nov & Sep-Dec & Jan-Feb \\
\hline \multicolumn{5}{|l|}{ C) Semideciduous species } \\
\hline Erythrophleum chlorostachys & 3.4 & Sep & Sep-Nov & Oct \\
\hline Xanthostemon paradoxus & 2.0 & Sep-Nov & Oct-Dec & Nov-Feb \\
\hline Buchanania obovata & 0.4 & Jul-Aug & Sep-Nov & Oct-Nov \\
\hline Eucalyptus clavigera & 0.3 & Jul-Sep & Aug-Oct & Oct \\
\hline Alphitonia excelsa & 0.1 & Aug-Nov & Jun-Nov & Feb-Apr \\
\hline Canarium australianum & 0.02 & Aug-Sep & Oct-Dec & Oct \\
\hline Timonius timon & 0.01 & Jul-Oct & Oct-Dec & Dec \\
\hline Dolichandrone filiformis & 0.01 & Jun-Aug & Sep-Dec & $\cdots$ \\
\hline Grevillea decurrens & 0.01 & Aug-Nov & Oct-Dec & Feb-Mar \\
\hline Petalostigma quadriloculare & 0.01 & Sep-Nov & Oct-Dec & Oct-Nov \\
\hline Planchonella pohlmaniana & 0.01 & Sep-Nov & Oct-Dec & Oct-Jan \\
\hline Pogonolobus reticulatus & 0.01 & Sep-Oct & Oct-Nov & Nov-Feb \\
\hline Strychnos lucida & 0.01 & Aug-Sep & Oct-Dec & $\cdots$ \\
\hline Syzygium bleeseri & 0.01 & Jun-Nov & Aug-Jan & Oct-Nov \\
\hline \multicolumn{5}{|l|}{ D) Fully deciduous species } \\
\hline Terminalia ferdinandiana & 2.0 & Jun-Nov & Oct-Dec & Nov-Jan \\
\hline Planchonia careya & 0.6 & Jul-Oct & Sep-Dec & Oct-Dec \\
\hline Brachychiton diversifolius & 0.3 & May-Oct & Sep-Nov & Aug-Sep \\
\hline Cycas armstrongii & 0.2 & May-Sep & Jul-Nov & $\ldots$ \\
\hline Croton arnhemicus & 0.1 & May-Oct & Oct-Dec & Nov-Jan \\
\hline Cochlospermum fraseri & 0.02 & Jun-Nov & Oct-Dec & Jun-Oct \\
\hline Ficus scobina & 0.02 & Jul-Oct & Oct-Dec & Jul-Aug \\
\hline Breynia cernua & 0.01 & May-Oct & Oct-Dec & Nov-Dec \\
\hline Antidesma ghaesembilla & 0.01 & Apr-Oct & Oct-Dec & Nov-Feb \\
\hline Brachychiton megaphyllus & 0.01 & Jun-Oct & Oct-Nov & Jul-Oct \\
\hline Clerodendrum floribundum & 0.01 & Jun-Nov & Oct-Dec & Dec-Feb \\
\hline Gardenia megasperma & 0.01 & Jul-Nov & Oct-Dec & $\ldots$ \\
\hline Vitex glabrata & 0.01 & Jul-Oct & Oct-Dec & Sep-Dec \\
\hline
\end{tabular}

$\dagger$ Basal area, measured as $\mathrm{m}^{2} / \mathrm{ha}$.

$\$$ Months of minimum canopy cover, where canopy cover is $<50 \%$ for semi- and fully deciduous species.

$\S$ Months of growth, in which new foliage is $>25 \%$ of canopy cover.

|| Months of peak flowering for a 2.5-yr period, from September 1992 to February 1995 Ellipses ( $\cdots$ ) indicate no record available.

inant species, Eucalyptus miniata and E. tetrodonta, differed significantly in the commencement of canopy reduction (early September and late September, respectively). The timing of canopy reduction also differed significantly between adults and saplings in both
E. miniata and E. tetrodonta. These two eucalypts were also significantly later than the other two eucalypts ( $E$. clavigera and $E$. porrecta) in commencing canopy reduction.

There was significant, but modest, interannual vari- 


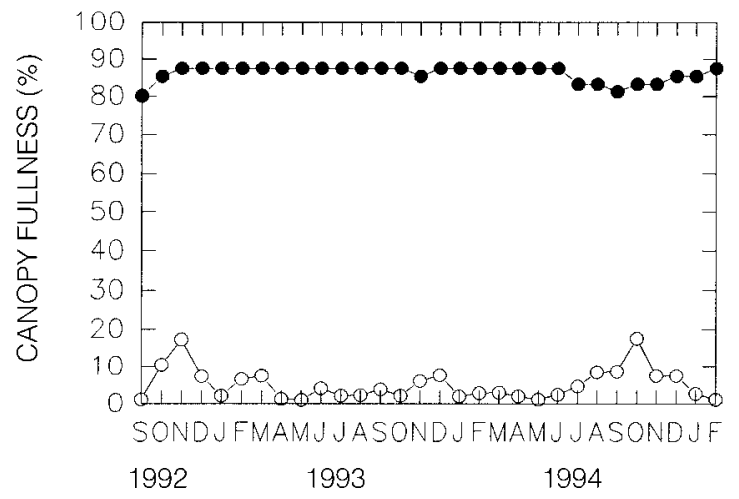

FIG. 4. Mean monthly canopy fullness $(\%, 0)$ and growth index $(\bigcirc)$ for evergreen species.

ation in the timing of canopy reduction (Table 3 ). Mean canopy reduction (pooled species) occurred about two weeks earlier in 1994 than in 1993. Variation within individual species was also substantial, as indicated by the standard errors of the species means (Table 3 ). For example, it was as much as 5-7 weeks in Eucalyptus miniata, E. porrecta, and Buchanania. Terminalia, in contrast, was more consistent between years in the timing of canopy reduction, as indicated by the lower standard errors of the species means (Table 3).

Variation in growth index.-Leaf flushing commenced over a range of times, from the early dry season to the late-dry/dry-wet transition period (Fig. 9; Tables 4 and 5). The peaks of growth in these 10 species were in the transitional, "buildup" period of October-November, but there were significant differences between species in the timing of initiation of growth (Fig. 9; Table 5) and the timing of peak growth (Fig. 9; Table 6). All individuals of all species had flushed to full canopy levels by the beginning of December in each year (Fig 9). The growth index of all species was low during the mid-late wet season.

In the two evergreen species, Eucalyptus miniata and E. tetrodonta, growth occurred more or less year-round (Fig. 9a-d). There was a minor growth peak early in the dry season (May-June), and these species continued to flush and produce expanded leaves throughout

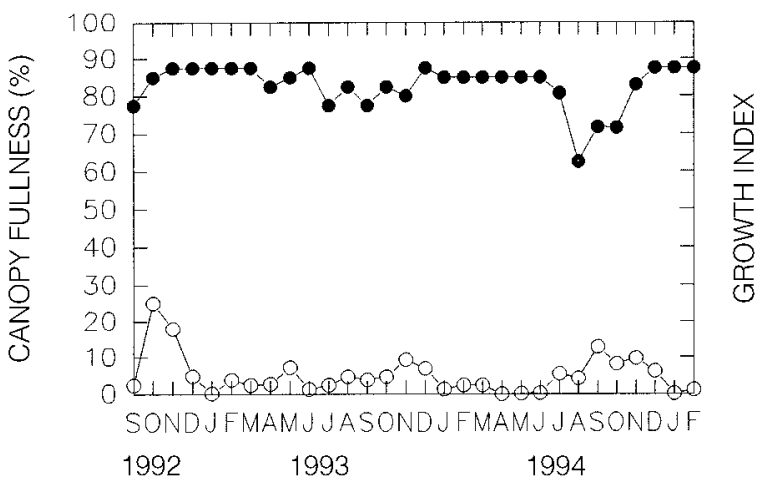

FIG. 5. Mean monthly canopy fullness $(\%, 0)$ and growth index $(\bigcirc)$ for brevideciduous species.

the dry season. There was a major peak of flushing and growth in October-November of each year; the extent of such growth was greater in E. miniata than in $E$. tetrodonta. E. miniata also commenced growth earlier than E. tetrodonta, both in the early part of the dry season, when growth commenced, and in the latter part of the dry season during the period of peak flush (Table 4). In both species, the mean time for commencement of growth was earlier in adults than in saplings (Table 4); this difference was significant for E. miniata, but not for E. tetrodonta. In both species, the cohort of leaves present at the commencement of the dry season had all but disappeared by the commencement of the following wet season; by December, the canopy consisted almost entirely of new, expanded foliage.

The brevi- and semideciduous species, Eucalyptus porrecta, E. clavigera, Buchanania, Erythrophleum, and Xanthostemon (Fig. 9e-1), generally commenced flushing prior to the arrival of any rain in each of the years of the study. Individuals within species were not synchronous in the timing of leaf flushing, and there was substantial interindividual variation within the semideciduous species, as indicated by the differences in the standard errors of the species means (Table 5). For example, as much as six weeks separated leaf flush in the earliest and latest flushing individuals of Buchanania and Xanthostemon. In comparison, Erythro-

TABLE 2. Mean values for three canopy abundance parameters and two growth parameters of the four phenological types. Standard errors of the difference between means for FlushTime and MaxGrow are 0.7 and 7.1, respectively (one-way ANOVA).

\begin{tabular}{lccccc}
\hline \hline \multicolumn{1}{c}{ Type } & MinCan $\dagger$ & Mon $<50 \% \neq$ & Mon@0\%§ & FlushTime\| & MaxGrowII \\
\hline Evergreen & 81.8 & 0.08 & 0.00 & 9.7 & 23.2 \\
Brevideciduous & 54.2 & 0.30 & 0.00 & 10.2 & 24.2 \\
Semideciduous & 23.9 & 2.25 & 0.04 & 11.7 & 41.6 \\
Fully deciduous & 0.0 & 4.68 & 1.96 & 11.5 & 51.0 \\
\hline
\end{tabular}

$\dagger$ Absolute minimum canopy fullness $(\%)$.

$\mp$ Number of months in which canopy fullness is $<50 \%$.

$\S$ Number of months in which canopy cover is zero.

$\|$ Time of peak flush, in months, where $9=$ beginning of September, $10=$ beginning of October, and 11 = beginning of November.

II Maximum growth index at the time of peak flush. 


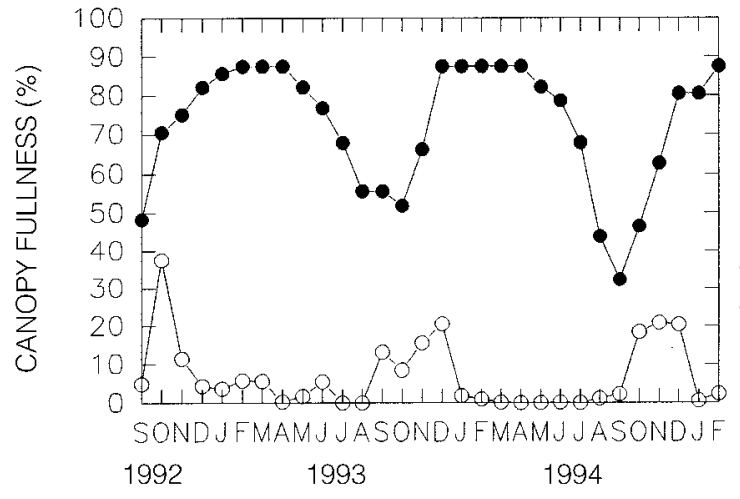

FIG. 6. Mean monthly canopy fullness $(\%, 0)$ and growth index $(\bigcirc)$ for semideciduous species.

phleum was more synchronous, as indicated by the lower standard error.

Of the fully deciduous species, Cochlospermum and Terminalia did not flush until after the initial, patchy falls of rain (Fig. 9i-1). Flushing did not appear to occur in either Terminalia or Cochlospermum until $\sim 25 \mathrm{~mm}$ of rain had fallen (Fig. 1), and flushing was more synchronous, than in the semideciduous species, with less than two weeks' difference between the earliest and latest flushing individuals. Planchonia, in contrast, was less synchronous than the other two fully deciduous species: some individuals flushed before, and others after, the first rains.

There was significant interannual variation in the timing of leaf flush in the semi- and fully deciduous species (Table 5.) Flushing commenced significantly earlier in 1992 than in either 1993 or 1994. Some species such as Erythrophleum were relatively consistent in flushing times between years, whereas others, such as Terminalia, commenced flushing one month earlier in 1992 than in 1993 and 1994.

The growth index peaked in all species 3-8 weeks after the period of minimum canopy abundance (Fig. 9), with an average time (pooled species) of about six weeks in both 1993 and 1994 (Table 6). This pattern occurred in all of the phenological groups, including the evergreens. As with growth initiation, there was significant interspecific variation in the magnitude of the delay between canopy minimum and growth peak, but there was no apparent trend between species from the different phenological groups, or between years (Table 6).

\section{Variation in pre-dawn leaf water potential in relation to leaf phenology}

All species showed seasonal variation in the levels of hydration, as measured by pre-dawn leaf or stem water potential (Fig. 9). Water potentials were highest in the late wet season $(\sim-0.1 \mathrm{MPa}$ in March). Dehydration commenced with the onset of the dry season, with water potentials falling to minimum values of

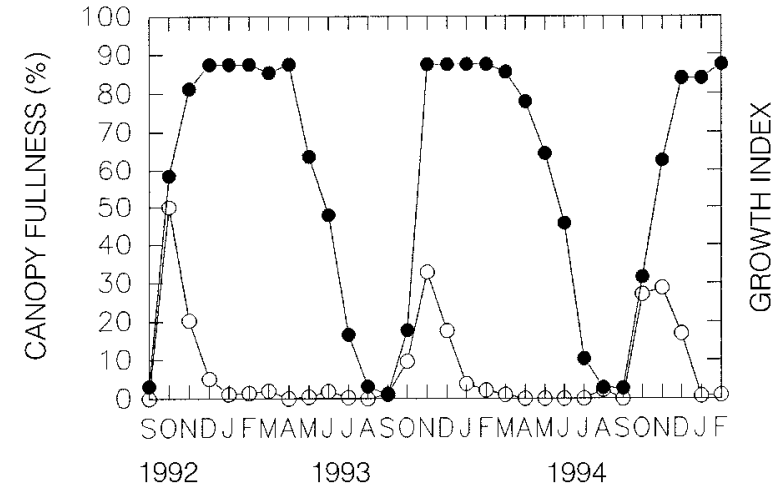

FIG. 7. Mean monthly canopy fullness $(\%, 0)$ and growth index $(\bigcirc)$ for fully deciduous species.
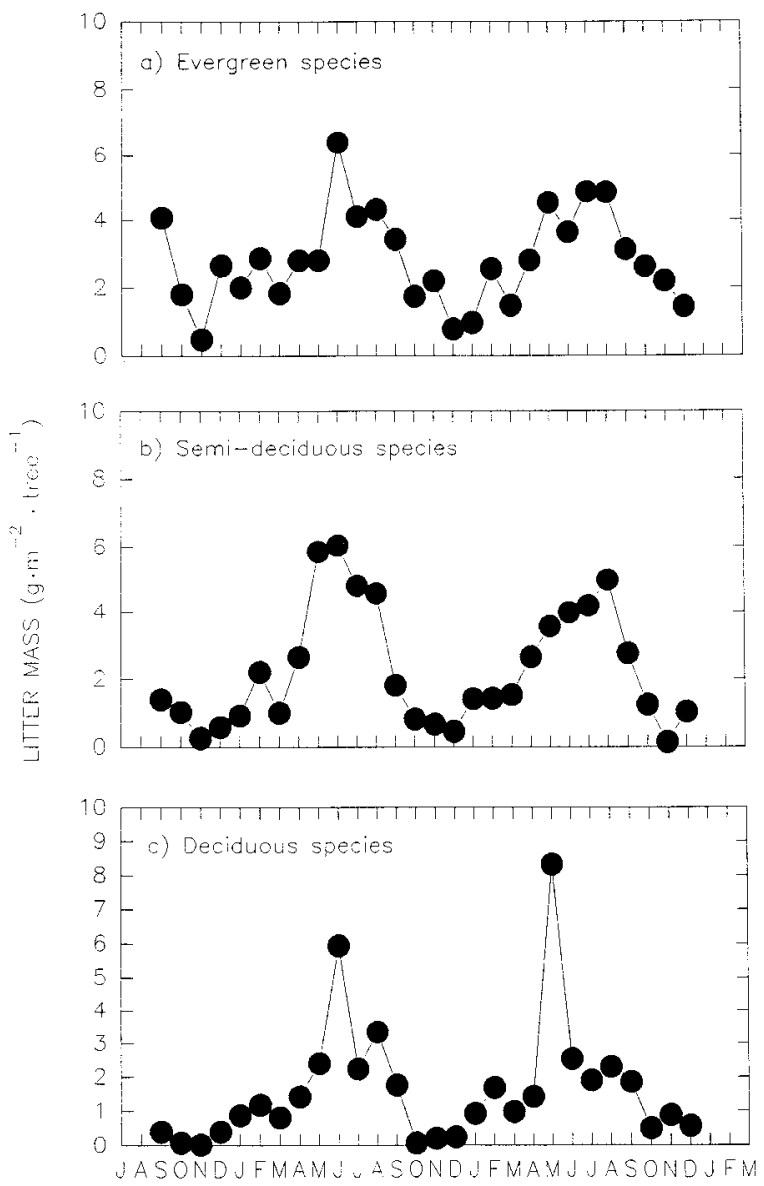

FIG. 8. Monthly pattern of litter fall $\left(\mathrm{g} \cdot \mathrm{m}^{-2} \cdot\right.$ tree $\left.^{-1}\right)$, from September 1992 to February 1995, in (a) evergreen species (Eucalyptus miniata and E. tetrodonta); (b) semideciduous species (E. clavigera, Erythrophleum chlorostachys, and Xanthostemon paradoxus); and (c) fully deciduous species (Cochlospermum fraseri, Planchonia careya, and Terminalia ferdinandiana). 

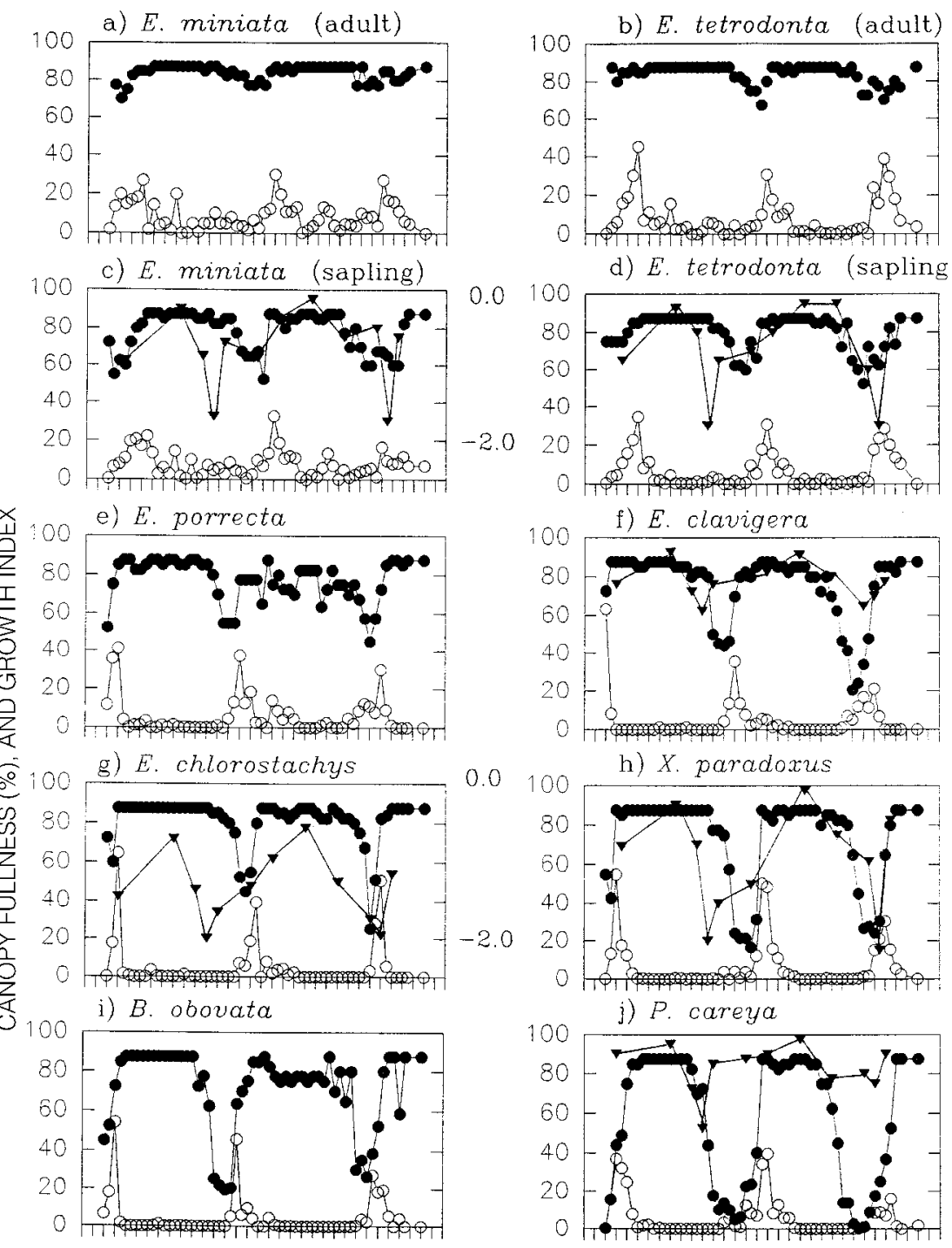

d) E. tetrodonta (sapling)
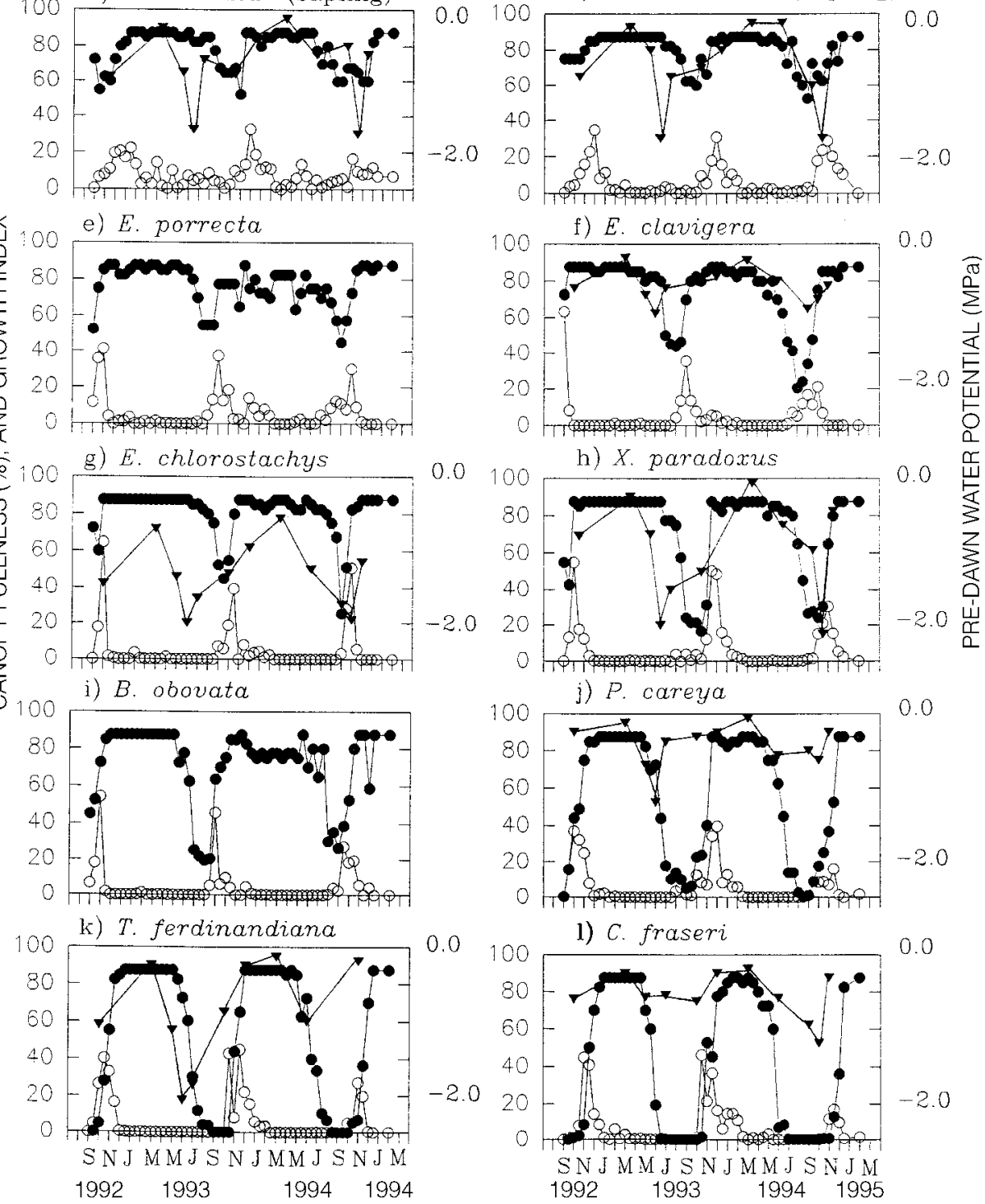

0.0

1) C. fraseri

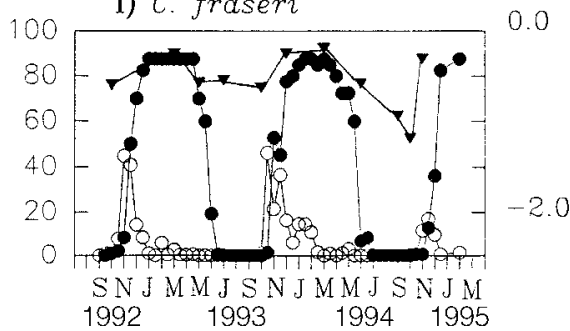

FIG. 9. Mean bimonthly values of canopy fullness $(\%, 0 ; n=10)$ and growth index $(\bigcirc ; n=10)$ for the 10 common savanna tree species from September 1992 to February 1995. (a) Eucalyptus miniata (adult stage); (b) E. tetrodonta (adult stage); (c) E. miniata (sapling stage); (d) E. tetrodonta (sapling stage); (e) E. porrecta; (f) E. clavigera; (g) Erythrophleum chlorostachys; (h) Xanthostemon paradoxus; (i) Buchanania obovata; (j) Planchonia careya; (k) Terminalia ferdinandiana; (1) Cochlospermum fraseri. Mean pre-dawn water potential for eight of the 10 species, throughout the study period, is shown by the closed triangles (data from Duff et al. [1997]).

$\sim-1 \mathrm{MPa}$ to $-1.5 \mathrm{MPa}$ in the mid-late dry season (July-October). Water potentials rose, and hence rehydration commenced, soon after seasonal minima had been reached.
There was significant interspecific and interannual variation in these patterns. The lowest minima and lowest average values over the course of the study occurred in two of the semideciduous species (Erythrophleum 
TABle 3. Mean timing of canopy reduction for 10 dominant woody species in a savanna at Solar Village, Australia. Numbers represent time (in months of the year) when canopy fullness dropped below $87.5 \%$ (the maximum value) for two consecutive bimonthly sample times. For each species, $n=10$ individuals.

\begin{tabular}{lccccc}
\hline \multicolumn{1}{c}{ Species } & Type $\neq$ & 1993 & 1994 & Mean & 1 SE \\
\hline Cochlospermum fraseri & FD & 4.65 & 4.45 & 4.55 & 0.22 \\
Terminalia ferdinandiana & FD & 5.90 & 5.00 & 5.45 & 0.13 \\
Planchonia careya & FD & 5.80 & 5.35 & 5.58 & 0.23 \\
Eucalyptus clavigera & SD & 6.75 & 6.00 & 6.38 & 0.21 \\
Buchanania obovata & SD & 6.05 & 7.70 & 6.88 & 0.26 \\
Eucalyptus porrecta & BD & 7.00 & 7.55 & 7.28 & 0.28 \\
Eucalyptus miniata (sapling) & EG & 8.50 & 7.34 & 7.92 & 0.36 \\
Xanthostemon paradoxus & SD & 8.45 & 8.05 & 8.25 & 0.18 \\
Eucalyptus tetrodonta (sapling) & EG & 8.54 & 8.23 & 8.39 & 0.18 \\
Erythrophleum chlorostachys & SD & 8.70 & 8.10 & 8.40 & 0.20 \\
Eucalyptus miniata (adult) & EG & 9.60 & 8.60 & 9.10 & 0.44 \\
Eucalyptus tetrodonta (adult) & EG & 10.30 & 9.10 & 9.70 & 0.22 \\
Year mean & & 7.51 & 7.14 & & \\
\hline
\end{tabular}

$\uparrow$ Note: Months of the year are represented numerically: 4.0, beginning of April; 4.5 , middle of April; 5.0, beginning of May; 5.5, middle of May; 6.0, beginning of June; 8.0, beginning of August; 9.0, beginning of September; 10.0, beginning of October.

† Phenological types: EG, evergreen; BD, brevideciduous; SD, semideciduous; FD, fully deciduous.

chlorostachys and Xanthostemon paradoxus). Cochlospermum fraseri, Planchonia careya, and Eucalyptus clavigera showed the highest minima and least seasonal variation. The two evergreen species (Eucalyptus miniata and E. tetrodonta) and one deciduous species (Terminalia ferdinandiana) showed intermediate values. Minimum levels of leaf water potential were reached in July in 1993, compared with October in 1994. This was a significant interseasonal difference (Duff et al. 1997), and the difference in timing was consistent among species.

The commencement of the decrease in average predawn leaf water potential with the onset of the dry season (March-May) occurred while all species were in full canopy. This pattern was consistent between years. However, there was interannual variation in the timing of both canopy reduction and leaf flushing, with respect to the seasonal patterns of pre-dawn water potential. The period of consistent reductions in canopy abundance (Table 3 ) commenced at about the time of attainment of minimum water potentials in 1993, but occurred 1-2 months prior to the attainment of such minima in 1994 (Fig. 9). The initial leaf flushing in 1993 occurred 1-2 months after the attainment of the seasonal minimum in water potential (i.e., after substantial rehydration following increasing water potentials), whereas the initial leaf flushing in 1994 was more or less coincident with the occurrence of minimum water potentials (Table 5; Fig. 9).

\section{DISCUSSION}

This study of a humid, eucalypt savanna in northern Australia identified a range of leaf phenologies, with respect to the degree of deciduousness, the timing of the major leaf phenophases, and the degree of synchrony both within and between species. Additionally, there was substantial variation in the timing of phenophases in relation to the seasonal patterns of wholeplant water status.

\section{Phenological types and deciduousness}

We recognized four main phenological types with respect to the degree of canopy retention/deciduous-

TABLE 4. Comparative timing of initiation of growth for adults and saplings of the two dominant evergreen eucalypts, Eucalyptus miniata and E. tetrodonta, in 1993 and 1994. Numerical nomenclature is as for Table 3.

\begin{tabular}{|c|c|c|c|c|c|c|}
\hline Species & Stage & 1992 & 1993 & 1994 & Mean & $1 \mathrm{SE}$ \\
\hline \multicolumn{7}{|c|}{ Early dry-season flush } \\
\hline E. miniata & Adult & $\ldots$ & 5.35 & 4.25 & 4.80 & 0.40 \\
\hline E. tetrodonta & Adult & $\ldots$ & 5.75 & 5.40 & 5.58 & 0.13 \\
\hline E. miniata & Sapling & $\ldots$ & 6.10 & 5.00 & 5.55 & 0.39 \\
\hline E. tetrodonta & Sapling & $\cdots$ & 6.44 & 5.50 & 5.97 & 0.33 \\
\hline \multicolumn{7}{|c|}{ Late dry-season or "buildup" flush } \\
\hline E. miniata & Adult & 9.95 & 10.35 & 9.90 & 10.07 & 0.11 \\
\hline E. miniata & Sapling & 10.50 & 10.65 & 10.20 & 10.45 & 0.19 \\
\hline E. tetrodonta & Adult & 11.05 & 11.05 & 10.40 & 10.83 & 0.31 \\
\hline E. tetrodonta & Sapling & 11.15 & 11.55 & 10.40 & 11.03 & 0.47 \\
\hline
\end{tabular}


TABLE 5. Mean timing of growth initiation in eight common species of semideciduous and fully deciduous woody plants in a savanna at Solar Village, Australia, in 1992, 1993, and 1994. Leaf phenological types and numerical representations of months are as in Table 3.

\begin{tabular}{lccrrrr}
\hline \hline \multicolumn{1}{c}{ Species } & Type & 1992 & 1993 & 1994 & Mean & 1 SE \\
\hline Eucalyptus clavigera & SD & 8.00 & 8.40 & 7.45 & 7.95 & 0.15 \\
Eucalyptus porrecta & BD & 8.45 & 8.25 & 7.80 & 8.17 & 0.23 \\
Buchanania obovata & SD & 8.65 & 8.80 & 9.60 & 9.01 & 0.24 \\
Erythrophleum chlorostachys & SD & 9.65 & 9.80 & 9.55 & 9.67 & 0.11 \\
Planchonia careya & FD & 9.25 & 9.80 & 10.25 & 9.77 & 0.25 \\
Xanthostemon paradoxus & SD & 9.55 & 10.50 & 9.75 & 9.93 & 0.17 \\
Cocholspermum fraseri & FD & 9.51 & 9.95 & 10.40 & 9.95 & 0.08 \\
Terminalia ferdinandiana & FD & 9.50 & 10.55 & 10.35 & 10.13 & 0.07 \\
Year mean & & 9.07 & 9.51 & 9.39 & & \\
\hline
\end{tabular}

ness: evergreen, part- or brevideciduous, semideciduous, and fully deciduous. Deciduousness is a feature of trees within savannas across the world, with pronounced seasonal reductions in canopy cover as the dry season progresses. There appears to be considerable variation in ecosystem-level patterns of deciduousness in the world's savannas. African savannas are mainly deciduous (Menaut and Cesar 1979, Chidumayo 1990), as are those of India (Shukla and Ramakrishnan 1982, Yadava 1990). In the Ilanos savannas of South America, evergreen species predominate (Monasterio and Sarmiento 1976, Sarmiento et al. 1985), although forest patches within the Ilanos are dominated by semideciduous or fully deciduous species (Medina 1982), as are the seasonally dry forests of Costa Rica (Borchert $1994 a)$.

Although about half of the species in this study were semideciduous or fully deciduous, approximately onequarter of the species, including the two community dominants, Eucalyptus miniata and E. tetrodonta, were evergreen. Because these two dominant species are evergreen, the overall projected foliage cover of the can- opy (sensu Specht 1981) in this savanna remains relatively high during the dry season (Duff et al. 1997). In the evergreen species, even though canopy is maintained to relatively high levels throughout the year, leaf longevity is less than one year, as indicated by the dominance of new, expanded leaves in December and the absence by this time, of most foliage known to have been present during the dry season.

Deciduousness in Terminalia and Planchonia appears to be obligate. Experiments with dry-season irrigation on these two species at another site near Darwin indicated quite clearly that leaf fall occurred during the dry season even when soil moisture remained at field capacity (B. A. Myers, R. J. Williams, G. A. Duff, and D. Eamus, unpublished data). Within Australia, deciduous tree species have mainly pantropical affinities (Bowman et al. 1988) and tend to be broad-leaved. Deciduous species from a wide range of genera are a feature of other tropical eucalypt savannas in Australia (Wilson et al. 1990, Bowman et al. 1991), although the abundance of such pantropical deciduous species generally declines along a gradient of decreasing mean

TABLE 6. Mean difference in time (months) between canopy minimum and growth index maximum in 10 dominant species of woody plant in a savanna at Solar Village, Australia, 1992-1994. Leaf phenological types are as in Table 3. Adult (ad) and sapling (sa) stages of Eucalyptus miniata and E. tetrodonta are shown separately. Species are ordered from minimum to maximum values as occurred in 1993.

\begin{tabular}{|c|c|c|c|c|c|c|c|c|}
\hline \multirow[b]{2}{*}{ Species } & \multirow[b]{2}{*}{ Type } & \multicolumn{2}{|c|}{$1992 \dagger$} & \multicolumn{2}{|c|}{1993} & \multicolumn{2}{|c|}{1994} & \multirow{2}{*}{$\begin{array}{c}3-y r \\
\text { mean }\end{array}$} \\
\hline & & Mean & $1 \mathrm{SE}$ & Mean & $1 \mathrm{SE}$ & Mean & $1 \mathrm{SE}$ & \\
\hline Eucalyptus miniata (sa) & EG & 2.00 & 0.34 & 1.00 & 0.32 & 2.39 & 0.51 & 1.80 \\
\hline Eucalyptus clavigera & $\mathrm{SD}$ & 0.75 & 0.15 & 1.05 & 0.11 & 0.75 & 0.08 & 0.85 \\
\hline Planchonia careya & FD & $\cdots$ & $\cdots$ & 1.05 & 0.40 & 1.20 & 0.46 & 2.47 \\
\hline Erythrophleum chlorostachys & $\mathrm{SD}$ & $\cdots$ & $\cdots$ & 1.10 & 0.24 & 0.75 & 0.24 & 0.90 \\
\hline Terminalia ferdinandiana & FD & $\ldots$ & $\ldots$ & 1.15 & 0.24 & 1.45 & 0.23 & 1.13 \\
\hline Eucalyptus porrecta & $\mathrm{BD}$ & 0.70 & 0.08 & 1.45 & 0.44 & 1.05 & 0.26 & 1.07 \\
\hline Eucalyptus miniata (ad) & EG & 0.70 & 0.23 & 1.57 & 0.61 & 1.57 & 0.19 & 1.28 \\
\hline Buchanania obovata & $\mathrm{SD}$ & 1.30 & 0.11 & 1.75 & 0.19 & 1.25 & 0.28 & 1.43 \\
\hline Eucalyptus tetrodonta (ad) & $\mathrm{EG}$ & 2.00 & 0.51 & 1.79 & 0.26 & 1.28 & 0.32 & 1.69 \\
\hline Cochlospermum fraseri & FD & $\cdots$ & $\ldots$ & 2.10 & 0.18 & 1.60 & 0.15 & 1.50 \\
\hline Xanthostemon paradoxus & $\mathrm{SD}$ & 0.90 & 0.16 & 2.15 & 0.39 & 1.25 & 0.17 & 1.43 \\
\hline Eucalyptus tetrodonta (sa) & EG & 2.30 & 0.24 & 2.56 & 0.54 & 2.39 & 0.23 & 2.41 \\
\hline Year average & & $\cdots$ & & 1.54 & & 1.41 & & 1.53 \\
\hline
\end{tabular}

$\uparrow$ Data were not available (ellipses) for several deciduous species in 1992 , as the exact time of canopy minimum occurred prior to the commencement of the study. 
annual rainfall from north to south in the Northern Territory (Egan and Williams 1995, Williams et al. 1996). This is in contrast to other tropical forests and savannas of the world, where, with increasing severity of the dry season, a greater proportion of species is deciduous (Reich 1995).

Three of the eucalypts examined in the present study were brevi- or semideciduous. The differences in the degree of deciduousness exhibited by the eucalypts in the present study may have been due to relative dominance within the forest stand. The evergreen eucalypts, E. miniata and E. tetrodonta, were substantially more abundant than the brevi- and semideciduous eucalypts (E. bleeseri, E. porrecta, and E. clavigera). Moreover, the saplings of both E. miniata and E. tetrodonta exhibited a greater degree of canopy reduction than did the adults. Thus, smaller trees might have had less access to groundwater or to deeper soil with residual soil moisture, and might have needed to shed more leaves (than larger trees of the same species) to balance transpirational area with water availability.

The differences in deciduousness among eucalypts may also be related to phylogeny. Deciduous eucalypts are known only from northern, tropical Australia; eucalypts in southern, temperate Australia are evergreen (Ashton and Attiwill 1994, Gill 1994). The deciduous eucalypts of the present study belong to the bloodwood subgenera Corymbia and Blakella (informal subgenera sensu Pryor and Johnson 1971). Species within these subgenera make up $\sim 50 \%$ of the eucalypt flora of northwestern Australia and include other species that are deciduous (Dunlop and Webb 1991). In contrast, the evergreen species of the present study belong to the subgenus Eudesmia, which has stronger phylogenetic links to subgenera that predominate in temperate Australia, Monocalyptus and Symphyomyrtus, than to Corymbia or Blakella (Ladiges et al. 1995).

Semideciduous species, which accounted for about one-quarter of the species surveyed in this study, do not appear to be a major functional group in savannas elsewhere in the world. Borchert's (1994a) classification of 39 tree species in Costa Rica recognized only evergreen and deciduous species. In an earlier classification, however, Reich and Borchert (1984) recognized a class of deciduous tree with asynchronous, prerain bud break (their class B species). This category appears to be similar to our semideciduous category in that, in both groups of species, leaf exchange from dry season to wet season is total, and bud break is more asynchronous among individuals in these species than it is in the fully deciduous species.

\section{Leaf flush and growth}

Leaf flushing in this savanna occurred primarily in the late dry season and buildup period (August-September-October). Of the dominant species, all but two (Terminalia and Cochlospermum) flushed prior to the occurrence of any rain. Flushing before the wet season was demonstrated by Wilson et al. (1996) in a similar community $200 \mathrm{~km}$ east of the present site, and by Bowman et al. (1991) for a savanna $200 \mathrm{~km}$ southeast of the present study site. It has been demonstrated in savannas and deciduous dry forests in the seasonal tropics elsewhere in the world by: Frankie et al. (1974) in Costa Rica; Menaut and Cesar (1979) in West Africa; Chidumayo (1990) in Zambia; Monasterio and Sarmiento (1976) in Venezuela; Shukla and Ramakrishnan (1982) in India; and Rundel and Becker (1987) in Central America. The phenomenon is not, however, universal in the savannas and forests of seasonal tropics. Flushing may commence at the beginning of the wet season (Opler et al. 1980, Prasad and Hedge 1986, Boinski and Fowler 1989, Bullock and Solis-Magallanes 1990, Borchert 1994a) or in the mid-wet season (Lieberman 1982, Lieberman and Lieberman 1984). The data of Frankie et al. (1974), Reich and Borchert (1984), and Borchert (1994a) indicate that both prerain and postrain flushing may occur in seasonally dry forests of Costa Rica, even in the same species

At Solar Village, Darwin, the peak period of leaf growth was October-November. This was 4-10 weeks after the point of minimum canopy abundance in all of the dominant species. This represents the "leaf exchange" pattern described for evergreen trees from other forests in the seasonal tropics (e.g., Reich and Borchert 1984, Sarmiento et al. 1985). In Costa Rica, the period of leaf exchange in the evergreen species was early in the dry season (Reich and Borchert 1984). At Solar Village, in comparison, it occurred in the late dry season. Production of new foliage more or less ceased at Solar Village soon after the commencement of the wet season, and most species were dormant by the midlate wet season. A similar pattern for the timing of dormancy has described for fully deciduous species (but apparently not for evergreen species) by Reich and Borchert (1984) in Cost Rica. Dormancy has also been described for the dry-wet transitional period for evergreen seasonal forests in West Africa (Longman and Jenik 1974), but that is clearly not the case for the present study.

The two dominant species, Eucalyptus miniata and E. tetrodonta, maintain growth throughout the dry season. They also flower during the dry season (Setterfield and Williams 1996). Dry-season growth has been demonstrated for trees in other northern Australian savannas (Fensham and Kirkpatrick 1992, Wilson et al. 1996) and elsewhere in the world (e.g., Aide 1992, although that particular study focused on the impacts of unseasonal dry-season rain). Dry-season growth has been proposed as a mechanism by which herbivory may be avoided and/or minimized (Aide 1988, 1992), although Fensham (1994) found little evidence for this in $E$. miniata or E.tetrodonta saplings in a savanna similar to that of the present study.

We have demonstrated substantial interspecific variation in the timing of major leaf phenological events 
such as leaf fall and leaf flush. Moreover, for some species such as Buchanania, Xanthostemon, and Planchonia, the interindividual variation in the timing of leaf fall and leaf flush is substantial. Such interindividual asynchrony in the timing of leaf flush within these deciduous and semideciduous species may reduce the impacts of regular dry-season fires, given that deciduous and semideciduous species are relatively fire sensitive (Cook and Williams 1995, Williams 1995), and that fire intensity increases as the dry season progresses (Braithwaite and Estbergs 1985, Williams 1995, Williams et al. 1997).

\section{Leaf phenology in Australia's humid wet-dry tropics: climate, synchrony, water status, and potential causative factors}

We have demonstrated significant interannual, interspecific, and intraspecific differences in the timing of leaf phenophases. The timing of these events in relation to variation in climate and internal plant water status raises questions concerning the causative factors associated with observed phenological patterns, a major issue in the ecology of the seasonal tropics.

In terms of floral and leaf phenology, there is a variety of opinion on the respective importance of exogenous, climatic triggers (e.g., van Schaik et al. 1993), vs. endogenous, whole-plant control (e.g., Reich and Borchert 1982, 1984, Borchert 1994a, b, c). Rapid decreases in soil moisture with the onset of the dry season have been associated with leaf fall (Reich and Borchert 1984). Wright and Cornejo (1990), however, found that dry-season irrigation had relatively little impact on the patterns of leaf fall. Hypotheses concerning the relationship between the timing of leaf flushing and growth and a number of potential climatic cues have been put forward by, for example, Opler et al. (1976; day length), Specht (1986; temperature), and Wright and van Schaik (1994; irradiance). Increases in soil moisture with the onset of the wet season may also act as a trigger to leaf flushing, where this phenomenon clearly occurs after the first rains. In contrast, Borchert (1980, 1994a), Reich and Borchert (1982, 1984), and Reich (1995) argue that the timing of flushing is controlled primarily endogenously (within the whole plant) via stem rehydration, following leaf loss, during the dry season. These authors argue against the need to view the timing of phenophases as being under the primary control of environmental cues, although, as Reich (1995) indicates, whole-plant mechanisms may be modified by environmental conditions. Similarly, Wang et al. (1992) argue for endogenous whole-plant control of bud burst, on the basis of correlations between the timing of bud burst and refilling of xylem elements following embolism.

Species remaining evergreen through the dry season are hypothesized to have access to groundwater (Borchert 1994a, Nepstad et al. 1994). Although this is most likely to be the case in the present study, the seasonal variation in pre-dawn water potential values was, in general, more extreme in the evergreen and semideciduous species than in the fully deciduous species. This is in contrast to the patterns observed for deciduous and evergreen species by Sobrado (1986). Moreover, the seasonal water potential minima of the present study (between -0.5 and $-2.0 \mathrm{MPa}$ ) were considerably higher than those of Sobrado (1986), who reported minima in the range of -2 to $-3 \mathrm{MPa}$ for a site in Venezuela where annual rainfall was $\sim 900 \mathrm{~mm}$. Borchert $(1994 b, c)$ reported minimum leaf water potential values of -2 to $-3 \mathrm{MPa}$ for deciduous species at a site in Costa Rica where rainfall was more similar to that of the Darwin region $(\sim 1500 \mathrm{~mm})$.

In the present study, leaf fall in two of the three fully deciduous species, Cochlospermum and Terminalia, commenced in the wet-dry transition period, at or about the time of attainment of seasonal minima in predawn leaf water potentials. This period is also a time of rapid decreases in both soil moisture (Fig. 1c) and relative humidity (Fig. 1b; Duff et al. 1997). Moreover, conductance in each of these three species appears to be very sensitive to both seasonal and diurnal changes in VPD (Myers et al. 1997). Thus, leaf fall in these deciduous species may be associated with declines in atmospheric moisture, in addition to declining internal water deficits (Duff et al. 1997).

The present data, and those of Duff et al. (1997) and Myers et al. (1997), lend general support to the ReichBorchert hypothesis that flushing is determined by changes in the internal water status of the whole plant. In 1993, in all species (evergreen, semideciduous, and fully deciduous), there was a rapid decline in pre-dawn leaf water potential during the early part of the dry season, from average levels of $\sim-0.25 \mathrm{MPa}$ in April to $-1.5 \mathrm{MPa}$ in June. Such declines reflect the decreased availability of water in the upper soil profile and increased evaporative demand. In all species, however, pre-dawn water potential subsequently rose to $\sim-1.0$ to $-0.5 \mathrm{MPa}$ between June and August. This rise in water potential was coincident with the period of leaflessness in the deciduous species and the period of maximum canopy decline in the semideciduous species. In the evergreen species, however, the rise in water potential occurred prior to any reduction in canopy decline. The substantial interannual variability in the timing of flushing indicates that photoperiod is an unlikely trigger.

Stem rehydration occurred in all species prior to the arrival of any rain. Flushing in the semideciduous and fully deciduous species occurred after the initial rises in water potential from the seasonal minima, but prior to the attainment of maximal water potentials during the mid-late wet season. This indicates that stem rehydration, as a consequence of the reduction in leaf area in the semi- and fully deciduous species, resulted in the near reattainment, by the late dry season, of water potentials similar to those of the mid-late wet season. 
Soil moisture levels at $1 \mathrm{~m}$ did not drop below $10 \%$ (volumetric) (i.e., permanent wilting point) at any time during the dry season of 1993, indicating that sufficient soil moisture reserves were available to support this process.

Increases in plant water potential in the semideciduous species occurred prior to the attainment of minimum canopy levels, indicating a potentially more complex control of transpiration than just simple leaf fall. Increased VPD, with the onset of the dry season, and consequent reductions in leaf conductance to water vapor, may account for such patterns in semideciduous species (Duff et al. 1997, Myers et al. 1997). Moreover, flushing occurred only after the initial rains in two of the three fully deciduous species (Cochlospermum and Terminalia), despite the occurrence of stem rehydration during the course of the dry season, indicating that, in these two species, increases in soil moisture with the commencement of the rains are also needed to trigger leaf flushing.

Our data show that, in several respects, the leaf phenology of trees in the Australian wet-dry tropics differs from that in other wet-dry tropical areas of the world. There appears to be a suite of semideciduous species, a life-form that appears to be uncommon in other regions of the world. Seasonal minima in pre-dawn water potential appear to be relatively high, particularly in the semideciduous species. However, despite these differences, the major phenophases appear to be under the control of the internal water status of the tree, as has been shown elsewhere in the seasonal tropics where leaf phenology has been studied in relation to tree water status.

\section{ACKNOWLEDGMENTS}

This study was supported by an Australian Research Council Large Grant. Ben Burchett, Jack Cusack, Bill Faylinson, Ian Fordyce, and Paul Varjak assisted with data collection. Eric Oldthwaite (Australian Bureau of Meteorology) provided unpublished climatic data. The manuscript was improved by the comments of D. H. Ashton, O. J. Berman, R. Borchert, C. R. Dunlop, A. M. Gill, R. H. Groves, H. G. Nelson, P. B. Reich, and J. C. Z. Woinarski. This is Tropical Ecosystems Research Centre Publication Number 955.

\section{Literature Cited}

Aide, T. M. 1988. Herbivory as a selective agent on the timing of leaf production in a tropical understorey community. Nature 336:574-575.

1992. Dry season leaf production: an escape from herbivory. Biotropica 24:532-537.

Ashton, D. H., and P. M. Attiwill. 1994. Tall open-forests Pages 157-196 in R. H. Groves, editor Australian Vegetation. Cambridge University Press, Cambridge, UK.

Boinski, S., and N. L. Fowler. 1989. Seasonal patterns in a tropical lowland forest. Biotropica 21:223-233.

Borchert, R. 1980. Phenology and ecophysiology of tropical trees: Erythrina poeppigiana O. F. Cook. Ecology 61 1065-1074.

- 1994a. Soil and stem water storage determine phenology and distribution of tropical dry forest trees. Ecology 75:1437-1449. 1994b. Water status and development of tropical trees during seasonal drought. Trees 8:115-125.

$1994 c$. Induction of rehydration and bud break by irrigation or rain in deciduous trees of a tropical dry forest in Costa Rica. Trees 8:198-204.

Bowman, D. M. J. S., B. A. Wilson, and C. R. Dunlop. 1988. Preliminary biogeographic analysis of the Northern Territory vascular flora. Australian Journal of Botany 36: 503-517.

Bowman, D. M. J. S., B. A. Wilson, and J. C. Z. Woinarski. 1991. Floristic and phenological variation in a northern Australian rocky Eucalyptus savanna. Proceedings of the Royal Society of Queensland 101:79-90.

Bowman, D. M. J. S., J. C. Z. Woinarski, and K. A. Menkhorst. 1993. Environmental correlates of tree species diversity in Stage III of Kakadu National Park, northern Australia. Australian Journal of Botany 41:649-660.

Braithwaite, R. W. and J. A. Estbergs. 1985. Fire pattern and woody vegetation trends in the Alligator Rivers region of northern Australia. Pages 359-364 in J. C. Tothill and J. J. Mott, editors. Ecology and management of the world's tropical savannas. Australian Academy of Science, Canberra, Australia.

Braithwaite, R. W., and J. Estbergs. 1988. Tuning in to the six seasons of the wet-dry tropics. Australian Natural History 22:445-449.

Brouliere, F., editor. 1983. Ecosystems of the world. 13. Tropical savannas. Elsevier, Amsterdam, The Netherlands.

Bullock, S. H., and J. A. Solis-Magallanes. 1990. Phenology of canopy trees of a tropical deciduous forest in Mexico. Biotropica 22:22-35.

Bureau of Meteorology. 1988. Climatic averages, Australia. Australian Government Printing Service, Canberra, Australia.

Burrows, D. M., and W. H. Burrows. 1992. Seed production and litter fall in some eucalypt communities in central Queensland. Australian Journal of Botany 40:389-403.

Chidumayo, E. N. 1990. Aboveground woody biomass structure and productivity in a Zambian woodland. Forest Ecology and Management 36:33-46.

Cook, G. D., and R. J. Williams. 1995. Is fire protection a greater risk to tree survival than prescribed burning? The effects of a single fire in a fire-protected savanna at Kapalga, Kakadu National Park. Proceedings, Bushfires'95, Hobart, Australia.

Duff, G. A., B. A. Myers, R. J. Williams, D. Eamus, I. Fordyce, and A. O'Grady. 1997. Seasonal patterns in canopy cover and microclimate in a tropical savanna near Darwin, northern Australia. Australian Journal of Botany 45:211-224.

Dunlop, C. R., G. J. Leach, P. K. Latz, M. J. Barritt, I. D. Cowie, and D. E. Albrecht. 1990. Checklist of vascular plants of the Northern Territory, Australia. Conservation Commission of the Northern Territory, Darwin, Australia.

Dunlop, C. R., and L. J. Webb. 1991. Flora and vegetation. Pages 41-61 in C. D. Haynes, M. G. Ridpath, and M. A. J. Williams, editors. Monsoonal Australia: landscape, ecology and man in the northern lowlands. Balkema, Rotterdam, The Netherlands.

Egan, J. L., and R. J. Williams. 1995. Life-form distributions of woodland plant species along a moisture availability gradient in Australia's monsoonal tropics. Australian Systematic Botany 9:205-217.

Fensham, R. J. 1990. Interactive effects of fire frequency and site factors in tropical Eucalyptus forests. Australian Journal of Ecology 15:255-266.

- 1994. Phytophagous insect-woody sprout interactions in tropical eucalypt forest. I. Insect herbivory. Australian Journal of Ecology 19:178-188. 
Fensham, R. J., and D. M. J. S. Bowman. 1992. Stand structure and the influence of overwood on regeneration in tropical eucalypt forest on Melville Island. Australian Journal of Botany 40:335-352.

Fensham, R. J., and J. B. Kirkpatrick. 1992. Soil characteristics and tree species distribution in the savanna of Melville Island, Northern Territory. Australian Journal of Botany 40:311-333.

Frankie, G. W., H. G. Baker, and P. A. Opler. 1974. Comparative phenological studies of trees in tropical wet and dry forests in the lowlands of Costa Rica. Journal of Ecology 62:881-919.

Genstat 5 Committee. 1994. Genstat 5 release 3 reference manual. Clarendon, Oxford, UK.

Gill, A. M. 1994. Eucalyptus open-forests. Pages 197-226 in R. H. Groves, editor. Australian vegetation. Cambridge University Press, Cambridge, UK.

Huntley, B. J., and B. H. Walker, editors. 1985. Ecology of tropical savannas. Ecological Studies Series Number 42. Springer-Verlag, New York, New York, USA.

Ladiges, P. Y., F. Udovicic, and A. Drinnan. 1995. Eucalypt phylogeny: molecules and morphology. Australian Systematic Botany 8:483-497.

Liebermann, D. 1982. Seasonality and phenology in a dry tropical forest in Ghana. Journal of Ecology 70:791-806.

Liebermann, D., and M. Liebermann. 1984. The causes and consequences of synchronous flushing in a dry tropical forest. Biotropica 16:193-201.

Longman, K. A., and J. Jenik. 1974. Tropical forest and its environment. Longman, London, UK.

McDonald, N. S., and J. McAlpine. 1991. Floods and drought: the northern climate. Pages 19-29 in C. D. Haynes, M. G. Ridpath, and M. A. J. Williams, editors. Monsoonal Australia: landscape, ecology and man in the northern lowlands. Balkema, Rotterdam, The Netherlands.

Medina, E. 1982. Physiological ecology of neotropical savanna plants. Pages 308-335 in B. J. Huntley and B. H Walker, editors. Ecology of tropical savannas. Ecological Studies Series Number 42. Springer-Verlag, New York, New York, USA.

Medina, E., and J. F. Silva. 1990. Savannas of northern South America: a steady state regulated by water-fire interactions on a background of low nutrient availability. Journal of Biogeography 17:403-413.

Menaut, J. C., and J. Cesar. 1979. Structure and primary productivity of Lamto savannas, Ivory Coast. Ecology 60 1197-1210.

Monasterio, M., and G. Sarmiento. 1976. Phenological strategies of plant species in the tropical savanna in the semideciduous forest of the Venezuelen llanos. Journal of Biogeography 3:325-356.

Myers, B. A., G. A. Duff, D. Eamus, R. J. Williams, I. Fordyce, and A. O'Grady. 1997. Seasonal variation in water relations of trees in a tropical savanna near Darwin, northern Australia. Australian Journal of Botany 45:225240 .

Nepstad, D. C., C. R. de Carvalho, E. A. Davidson, P. H. Jipp, P. A. Lefebrve, G. H. Negreiros, E. D. da Silva, T A. Stone, S. E. Trumbore, and S. Vieria. 1994. The role of deep roots in the hydrological and carbon cycles of Amazonian forests and pastures. Nature 372:666-669.

Opler, P. A., G. W. Frankie, and H. G. Baker. 1976. Rainfall as a factor in the release, timing, and synchronization of anthesis by tropical trees and shrubs. Journal of Biogeography 3:231-236.

Opler, P. A., G. W. Frankie, and H. G. Baker. 1980. Comparative phenological studies of treelet and shrub species in tropical wet and dry forests in the lowlands of Costa Rica. Journal of Ecology 68:167-188.
Prasad, S. N., and M. Hedge. 1986. Phenology and seasonality in the tropical deciduous forest of Bandipur, South India. Proceedings of the Indian Academy of Science (Plant Science) 96:121-133.

Pryor, L. D., and L. A. S. Johnson. 1971. A classification of the eucalypts. Australian National University, Canberra, Australia.

Reich, P. B. 1995. Phenology of tropical forests: patterns, causes, and consequences. Canadian Journal of Botany 73:164-174.

Reich, P. B., and R. Borchert. 1982. Phenology and ecophysiology of the tropical tree Tabebuia neochrysantha (Bignoniaceae). Ecology 63:294-299.

Reich, P. B., and R. Borchert. 1984. Water stress and tree phenology in a tropical dry forest in the lowlands of Costa Rica. Journal of Ecology 72:61-74.

Rundel, P. W., and P. F. Becker. 1987. Cambios estacionales en las relaciones hidricias y en la fenologia vegetativa de plantas del estrata bajo del bosque tropical de la Isla de Barro Colorado, Panama. Revista de Biologia Tropical 35 : 71-84.

Sarmiento, G., G. Goldstein, and F. Meinzer. 1985. Adaptive strategies of woody species in neotropical savannas. Biological Review 60:315-355.

Sarmiento, G., and M. Monasterio. 1983. Life-forms and phenology. Pages 79-108 in F. Brouliere, editor. Ecosystems of the world. 13. Tropical savannas. Elsevier, Amsterdam, The Netherlands.

Setterfield, S. A., and R. J. Williams. 1996. Patterns of flowering and seed production in Eucalyptus miniata and E. tetrodonta in a tropical savanna woodland, northern Australia. Australian Journal of Botany 44:107-122.

Shukla, R. P., and P. S. Ramakrishnan. 1982. Phenology of trees in a subtropical forest in northeastern India. Vegetatio 49:103-109.

Sobrado, M. 1986. Aspects of tissue water relations and seasonal changes of leaf water potential components of evergreen and deciduous species coexisting in tropical dry forests. Oecologia (Berlin) 68:413-416.

Specht, R. L. 1981. Foliage projective cover and standing biomass. Pages 10-21 in A. N. Gillison and D. J. Anderson, editors. Vegetation classification in Australia. CSIRO, Canberra, Australia

1986. Phenology. Pages 78-91 in H. T. Clifford and R. L. Specht, editors. Tropical plant communities: their resilience, functioning, and management. Department of Botany, University of Queensland, Brisbane, Australia.

Taylor, J. A., and D. Tulloch. 1985. Rainfall in the wetdry tropics: Extreme events at Darwin and similarities between years in the period 1870-1983. Australian Journal of Ecology 10:281-295.

Tothill, J. C., and J. J. Mott, editors. 1985. Ecology and management of the world's savannas. Australian Academy of Science, Canberra, Australia.

van Schaik, C. P., J. W. Terborgh, and S. J. Wright. 1993. The phenology of tropical forests: adaptive significance and consequences for primary producers. Annual Review of Ecology and Systematics 24:353-377.

Wang, J., N. E. Ives, and M. J. Lechowicz. 1992. The relation of foliar phenology to xylem embolism in trees. Functional Ecology 6:469-475.

Williams, R. J. 1995. Tree mortality in relation to fire intensity in a tropical savanna of the Kakadu region, Northern Territory, Australia. CALMScience Supplement 4:7782 .

Williams, R. J., G. A. Duff, D. M. J. S. Bowman, and G. A. Cook. 1996. Variation in the composition and structure of tropical savannas as a function of rainfall and soil 
texture along a large-scale climatic gradient in the Northern Territory. Journal of Biogeography 23:747-756.

Williams, R. J., A. M. Gill, and P. H. R. Moore. 1997. Seasonal changes in fire behaviour in a tropical savanna in northern Australia. International Journal of Wildland Fire, in press.

Wilson, B. A., P. S. Brocklehurst, M. J. Clark, and K. J. M. Dickenson. 1990. Vegetation of the Northern Territory, Australia. Conservation Commission of the Northern Territory, Technical Report Number 49, Darwin, Australia.
Wilson, B. A., J. Russell-Smith, and R. J. Williams. 1996. Terrestrial vegetation. Pages 57-79 in C. M. Finlayson and I. Von Oertzen, editors. Landscape and vegetation of the Kakadu region. Kluwer, Dordrecht, The Netherlands. Wright, S. J., and F. H. Cornejo. 1990. Seasonal drought and leaf fall in a tropical forest. Ecology 71:1165-1175. Wright, S. J., and C. P. van Schaik. 1994. Light and the phenology of tropical trees. American Naturalist 143: 192-199.

Yadava, P. S. 1990. Savannas of northeast India. Journal of Biogeography 17:387-396. 